\title{
Metastatic suppressor CD44 is related with oxidative stress in breast cancer cell lines
}

\author{
C. ECHIBURÚ-CHAU ${ }^{1}$, D. ROY $^{2}$ and G.M.CALAF ${ }^{1,3}$ \\ ${ }^{1}$ Instituto de Alta Investigación, Universidad de Tarapacá, Arica, Chile; ${ }^{2}$ Department of Natural Sciences, \\ Hostos College of the City University of New York, Bronx, NY; ${ }^{3}$ Center for Radiological \\ Research, Columbia University Medical Center, New York, NY, USA
}

Received March 31, 2011; Accepted July 14, 2011

DOI: 10.3892/ijo.2011.1154

\begin{abstract}
Evidence has accumulated on the role of reactive oxygen species (ROS) in metastasis since surgical removal of tumors generates oxidative stress promoting metastasis and cell growth. Metastasis consists of a cascade of events which allow the cell to survive in target tissues and influence several processes such as dissemination from tumor tissue, transport in blood/lymphatic vessels, invasion and homing of malignant cells. A cDNA oligoarray was used to determine whether alterations of metastatic genes are associated with oxidative stress in breast cancer cell lines. The cell lines used for the experiments were derived from a pre-existent in vitro breast cancer progression model originated in our laboratory. The cDNA array showed alterations in functional gene groups related with cell-cell and cell-matrix interaction molecules, such as caveolin-1; metastasis suppressor genes, such as CD44; metastasis-associated proteases, such as cathepsin D and the protease inhibitor, plasminogen activator inhibitor type 1 . The changes of the selected genes were validated by differential display-RT-PCR as well as by protein expression assessed by Western blot analysis. It was found that the cell line, called Tumor 2 with down-regulation of basal ROS and manganese superoxide dismutase (MnSOD) expression as a constitutive pattern of this cell line, presented alterations in genes that confer metastatic potential in comparison to the Alpha5 cell line, showing overexpression of basal MnSOD and high levels of ROS. Interesting, it was to found that CD44, considered a metastatic suppressor gene, was influenced by ROS, measured by hydrogen peroxide treatments, as seen by decreased CD44 protein expression in the Alpha5 cell line in a compensatory response to increased MnSOD protein expression. In conclusion, alterations of metastatic genes in malignant breast cancer cell lines were observed in relation to ROS and basal levels of antioxidant enzymes.
\end{abstract}

Correspondence to: Dr Gloria M. Calaf, Instituto de Alta Investigación, Universidad de Tarapacá, Calle Antofagasta 1520, Arica, Chile

E-mail: gmc24@columbia.edu

Key words: metastasis, CD44, oxidative stress, breast cancer

\section{Introduction}

High concentrations of reactive oxygen species (ROS) can damage cellular proteins, lipids and DNA, which are related to several human diseases including cardiovascular and neurodegenerative diseases as well as cancer $(1,2)$. It is well documented that ROS act in multiple signaling cascades related to various behaviors in cancer cell, such as survival, proliferation, angiogenesis and metastasis. ROS are thus considered responsible for initiation, development, progression, invasion and metastasis of cancers (3-5). Clinical evidence has implicated the fundamental role of ROS in invasion and migration $(6,7)$. Studies have found that surgical removal of tumors generates ROS which promote tumor growth and metastasis (8-11).

Tumor metastasis consists of a complex cascade of events, including dissemination of malignant cells from tumor tissue, transport in blood/lymphatic vessels, invasion and homing $(12,13)$ which allow the cell to survive in target tissues. A high mobility and protease activity as well as altered expression of adhesion molecules are the principal characteristics to obtain an invasive pattern of cancer cells (14). The activation or suppression of the genes involved in metastatic processes are considered pivotal for the cell to acquire an aggressive phenotype.

A pre-existent in vitro human breast epithelial cell cancer progression model from our laboratory $(15,16)$, was used in this study to examine the metastatic potential of two tumorigenic cell lines with different phenotypes of malignancy. Previous studies of this model (17) reported a cell cycle arrest in a cell line called Alpha5 associated with high concentration of basal ROS, measured by hydrogen peroxide levels, and overexpression of basal manganese superoxide dismutase (MnSOD) enzyme. Furthermore, an aberrant cell proliferation in a cell line called Tumor 2 associated with low concentrations of basal ROS and down-regulation of basal MnSOD was also reported. It is important to state that basal levels of ROS and antioxidant enzymes are constitutive patterns of these two malignant cell lines.

MnSOD enzyme is considered one of the principal cellular antioxidants that catalyze the conversion of superoxide radical to hydrogen peroxide. It has been shown that an elevated content of SOD2, a gene encoding the MnSOD protein, in addition to a diminished level of CAT, a gene encoding catalase 


\section{RELATIONSHIP BETWEEN MALIGNANT PHENOTYPE AND} OXIDATIVE STRESS PATTERN

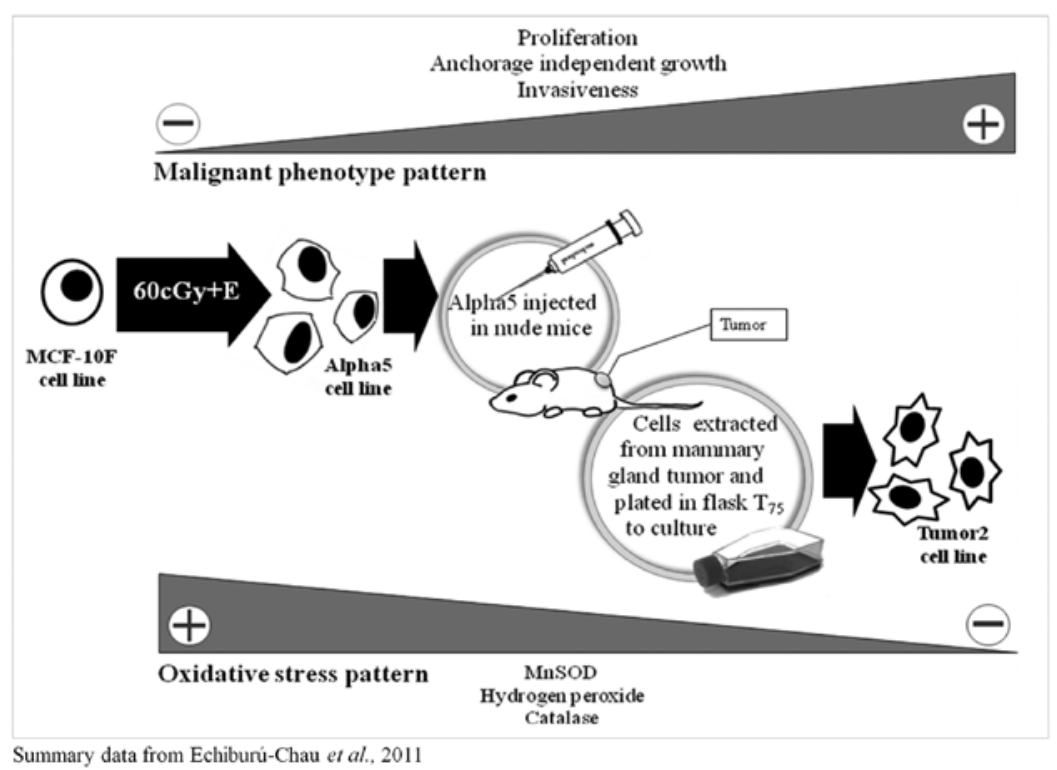

Figure 1. Relationship between malignant phenotype and oxidative stress pattern of the malignant breast cancer cell lines, Alpha5 and Tumor2, from the preexistent model. This pattern is the constitutive basal condition of the cell lines. The Alpha5 cell line originated from the MCF-10F cell line treated with double doses of ionizing radiation (60cGy) plus estrogen (E). Tumor2 is a cell line obtained from cells extracted from a tumor induced by injection of Alpha5 cells in nude mice and subsequent plated in a T75 flask to culture. The malignant phenotype pattern (determined by proliferation, anchorage-independent growth and invasiveness) is enhanced from the Alpha5 to the Tumor2 cell line. On the other hand, the oxidative stress pattern (determined by MnSOD, hydrogen peroxide and catalase levels) is decreased from the Alpha5 to the Tumor2 cell line. The scheme is based on results reported in Echiburú-Chau et al, 2011 (17).

protein, are correlated with increased metastasis, proliferation and resistance to apoptosis $(18,19)$. Frequently, the downregulation of MnSOD protein expression has been linked to tumor cell lines and the restoration of this protein indicates a reduction of the cell growth and proliferation, thus suggesting that MnSOD acts as a tumor suppressor gene $(20,21)$. It has been shown that transfection of MnSOD cDNA in the MCF-7 cell line, a malignant cell line dependent on estrogen, reduced cell growth and suppressed progression to a malignant phenotype (22). In addition, the growth of metastatic tumor cells, has been successfully suppressed through SOD injection in male C57BL/6 (6-week-old) mice, indicating that the elimination of ROS inhibited tumor metastasis (23). On the other hand, high levels of basal MnSOD expression have been correlated with an increase of invasive and metastatic properties $(24,25)$.

The metastatic genes expressed under oxidative stress, which determine such cancer cell responses is still unclear due to several variables. In vitro studies have shown that numerous cancer cell lines contain elevated levels of MnSOD and decreased levels of catalase, and changes in hydrogen peroxide levels correlates with increased metastasis, proliferation, and resistance to apoptosis $(18,26)$. Since progression and metastasis are associated with a series of variables, including cell type, MnSOD, catalase and ROS levels, such as superoxide radical and hydrogen peroxide among others, contradictory data have been reported (23).

During the last decade several observations have been reported concerning the expression of CD44 and its variants in cancer progression. Several studies have associated CD44 expression with tumor progression and metastasis. CD44 is particularly interesting to study due to its close relationship with MnSOD, a candidate tumor suppressor (27), and due to the fact that CD44-positive cells exhibit a favorable prognosis (28).

The present study analyzed the presence of altered metastatic genes in breast cancer cells with altered basal oxidative stress patterns in two tumorigenic cell lines, called Alpha5 and Tumor2, from a pre-existent in vitro breast cancer model using cDNA oligoarray technology.

\section{Materials and methods}

Cell culture. Two malignant and tumorigenic breast cancer cell lines, called Alpha5 and Tumor2, were used from a pre-existent in vitro cell model (15). Such cells have different anchorageindependent growth, invasion and tumorigenic capabilities and distinctive MnSOD, hydrogen peroxide and catalase basal levels (Fig. 1). The spontaneously immortalized breast epithelial cell line, MCF-10F (ATCC, Manassas, VA, USA), was used as a control. The cell lines were cultured with Dulbecco's modified Eagle's medium (DMEM)/F-12 (1:1) supplemented with $100 \mathrm{U} / \mathrm{ml}$ penicillin, $100 \mathrm{mg} / \mathrm{ml}$ streptomycin, $2.5 \mathrm{mg} / \mathrm{ml}$ amphotericin B (all from Life Technologies, Grand Island, $\mathrm{NY}$ ), $10 \mathrm{mg} / \mathrm{ml}$ insulin (Sigma-Aldrich, St. Louis, MO), 5\% equine serum (Biofluids, Rockville, MD), $0.5 \mathrm{mg} / \mathrm{ml}$ hydrocortisone (Sigma) and $0.02 \mathrm{mg} / \mathrm{ml}$ epidermal growth factor (Collaborative Research, Bedford, MA). The cells were incubated at $37^{\circ} \mathrm{C}$ with $5 \% \mathrm{CO}_{2}$ up to $70 \%$ of confluence.

Extraction of $m R N A$. Total-RNA was isolated using TRIzol reagent (Invitrogen Corp., Long Island, NY) to be used on cDNA array. The RNA sample was first measured by a spec- 
Table I. Primers of differentially expressed genes selected for differential display-reverse transcriptase-polymerase chain reaction (DD-RT-PCR) analysis.

\begin{tabular}{|c|c|c|c|}
\hline GenBank ID & Gene name & Product length (bp) & Primer $\left(5^{\prime}-3^{\prime}\right)$ \\
\hline NM_001753 & Caveolin 1 & 468 & $\begin{array}{l}\text { Sense, gctcacttctgggcttcatc } \\
\text { Antisense, tcctcccccatcttctttct }\end{array}$ \\
\hline M59040 & $C D 44$ & 402 & $\begin{array}{l}\text { Sense, catctaccccagcaacceta } \\
\text { Antisense, agcttttcttctgcccaca }\end{array}$ \\
\hline M11233 & Cathepsin D & 437 & $\begin{array}{l}\text { Sense, gctacaagctgtccccagag } \\
\text { Antisense, ctctacccccaccaaacaga }\end{array}$ \\
\hline M16006 & Plasminogen activator inhibitor type 1 & 460 & $\begin{array}{l}\text { Sense, tctcaggaagtccagccact } \\
\text { Antisense, accctctggctggtaggttt }\end{array}$ \\
\hline X00351 & $\beta$-actin & 569 & $\begin{array}{l}\text { Sense, actacctcatgaagatcctc } \\
\text { Antisense, ctagaagcatttgcggtggacgatgg }\end{array}$ \\
\hline
\end{tabular}

trophotometer (the ratio of absorbance reading at $260 / 280 \mathrm{~nm}$ $>1.8$ ) and then electrophoresed on $1.5 \%(\mathrm{w} / \mathrm{v})$ denaturing formaldehyde/agarose gel to check its quality and purity.

Tumor metastasis cDNA expression array. The GEArray ${ }^{\circledR}$ Q Series Human Tumor Metastasis Gene Array (\#HS-007) was purchased from SuperArray (Bethesda, MD, USA). The array was chosen to profile the gene expression of a panel of $96 \mathrm{key}$ genes that encode for different classes of proteins including growth factors and their receptors, ECM components, proteases and their inhibitors, oncogenes and tumor suppressors, and other related genes involved in metastasis pathways. This array included 3 blanks, 3 negative reference spots ( $p U C 18$ DNA) and 10 housekeeping genes ( $\beta$-actin, GAPDH, cyclophilin $A$ and ribosomal protein L13a). Protocol and data analysis of arrays were performed according to the manufacturer's instructions and the gene list and array position for expression profiling were available at the SuperArray Bioscience Corporation website. Total-RNA obtained from the three cell lines were used for the synthesis of cDNA probes with biotin16-dUTP (Roche, Indianapolis, IN). An annealing mixture was prepared by mixing $\sim 1.0 \mu \mathrm{g}$ of total-RNA with $3 \mu \mathrm{l}$ of Buffer A (GE primer mix) (SuperArray, Bethesda, MD, USA) and the final volume was adjusted to $10 \mu 1$. The cDNA probes were then denatured by heating at $94^{\circ} \mathrm{C}$ for $5 \mathrm{~min}$, and hybridized overnight at $60^{\circ} \mathrm{C}$ with continuous gentle agitation in GEAhyb solution to nylon membranes spotted with gene specific fragments. Subsequently, array membranes were washed twice in $2 \mathrm{X} \mathrm{SSC} / 1 \%$ SDS for $15 \mathrm{~min}$ each, followed by another wash in $0.1 \mathrm{X} \mathrm{SSC} / 0.5 \%$ SDS for $15 \mathrm{~min}$. Hybridized probes were visualized with the CPD-Star Chemiluminescent Detection kit according to the company protocol (SuperArray). Array images were recorded using Kodak BioMax light film (SigmaAldrich) after multiple exposures of 1-5 min. Images were scanned and converted into grayscale and 16-bit tiff format, and the numerical data representing the expression levels of each gene on the arrays were quantified using the software Image Quant 5.2 (Molecular Dynamics) to obtain the volume data. Raw data were intra-normalized with the signal intensity of the $A C T B$ gene after subtracting the mean intensities of the negative control spots (pUC18 plasmid DNA) and blank spots. Inter-normalization was performed with control normal bone signal intensities to minimize the interference between adjacent strong hybridization signals. The level of expression of a gene was obtained by comparing its expression in malignant cells and in a control cell line. The expression was up-regulated if the ratio was $\geq 2.0$ and down-regulated if the ratio $\leq 0.5$, and unchanged if the ratio was between 0.5 and 2.0 and these genes were omitted from the analysis.

Differential display-reverse transcriptase-PCR (DD-RT-PCR). To validate the selected differentially expressed genes in the cDNA array DD-RT-PCR was performed. Total-RNA was isolated using TRIzol reagent (Invitrogen Corp.). The purified RNA sample was first measured with a spectrophotometer (the ratio of absorbance reading at $260 / 280 \mathrm{~nm}>1.8$ ) and then electrophoresed on $1.5 \%(\mathrm{w} / \mathrm{v})$ denaturing formaldehyde/agarose gel to check its quality and purity. Total-RNA of $3 \mu \mathrm{g}$ was used for reverse transcription-polymerase chain reaction (RT-PCR). The first-strand cDNA was synthesized with primer oligo(dt) to hybridize to 3' poly (A) tails. To confirm their similar expression in all samples human $\beta$-actin was used as a control amplifier set. Table I shows the primers of the genes selected for DD-RT-PCR analyses, including the gene name, product length and sense and antisense primers used (all primers from Sigma-Aldrich). These primers were developed using the Primer3 input software (version 0.4.0). To confirm the differential expression of the 4 selected genes, different amounts of cDNA and a varied number of PCR cycles were used to generate gene-specific probes. A linear increase was observed in product generation in all cases (log phase). Then $1 \mu \mathrm{l}$ of cDNA and the specific DD-RT-PCR setup for each gene were determined. Table II shows the protocol of DD-RT-PCR analyses including the gene name, number of cycles in the log phase selected, PCR steps and temperature/time used. For all PCR reactions, an initial cycle of $94^{\circ} \mathrm{C}$ for 2 min was necessary to activate Taq polymerase and a final cycle of $72^{\circ} \mathrm{C}$ for 2 min was utilized to complete the amplicon produced. The PCR product was electrophoresed on a $2 \%(\mathrm{w} / \mathrm{v})$ agarose gel. Differentially expressed gene-specific DNA bands were then photographed and analyzed with Adobe 
Table II. Differential display-reverse transcriptase-polymerase chain reaction (DD-RT-PCR) configuration.

\begin{tabular}{|c|c|c|c|}
\hline Gene name & No. cycles & PCR steps & Temperature/time \\
\hline Caveolin 1 & 23 & $\begin{array}{l}\text { Denaturation } \\
\text { Annealing } \\
\text { Extension }\end{array}$ & $\begin{array}{l}94^{\circ} \mathrm{C} / 30 \mathrm{sec} \\
55^{\circ} \mathrm{C} / 30 \mathrm{sec} \\
72^{\circ} \mathrm{C} / 30 \mathrm{sec}\end{array}$ \\
\hline$C D D 44$ & 24 & $\begin{array}{l}\text { Denaturation } \\
\text { Annealing } \\
\text { Extension }\end{array}$ & $\begin{array}{l}94^{\circ} \mathrm{C} / 30 \mathrm{sec} \\
60^{\circ} \mathrm{C} / 30 \mathrm{sec} \\
72^{\circ} \mathrm{C} / 30 \mathrm{sec}\end{array}$ \\
\hline Cathepsin D & 23 & $\begin{array}{l}\text { Denaturation } \\
\text { Annealing } \\
\text { Extension }\end{array}$ & $\begin{array}{l}94^{\circ} \mathrm{C} / 30 \mathrm{sec} \\
55^{\circ} \mathrm{C} / 30 \mathrm{sec} \\
72^{\circ} \mathrm{C} / 30 \mathrm{sec}\end{array}$ \\
\hline Plasminogen activator inhibitor type 1 & 23 & $\begin{array}{l}\text { Denaturation } \\
\text { Annealing } \\
\text { Extension }\end{array}$ & $\begin{array}{l}94^{\circ} \mathrm{C} / 30 \mathrm{sec} \\
55^{\circ} \mathrm{C} / 30 \mathrm{sec} \\
72^{\circ} \mathrm{C} / 30 \mathrm{sec}\end{array}$ \\
\hline$\beta$-actin & 14 & $\begin{array}{l}\text { Denaturation } \\
\text { Annealing } \\
\text { Extension }\end{array}$ & $\begin{array}{l}94^{\circ} \mathrm{C} / 45 \mathrm{sec} \\
59^{\circ} \mathrm{C} / 40 \mathrm{sec} \\
72^{\circ} \mathrm{C} / 60 \mathrm{sec}\end{array}$ \\
\hline
\end{tabular}

For each PCR reaction an initial cycle of $94^{\circ} \mathrm{C}$ for 2 min was necessary to activate Taq polymerase and a final cycle of $72^{\circ} \mathrm{C}$ for 2 min was utilized to complete the amplicon produced.

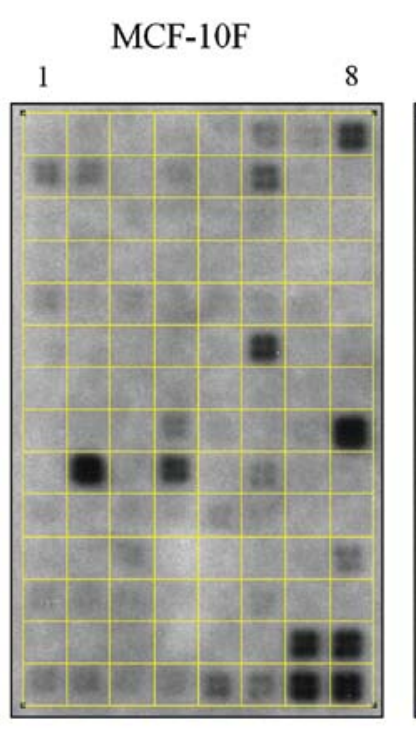

105

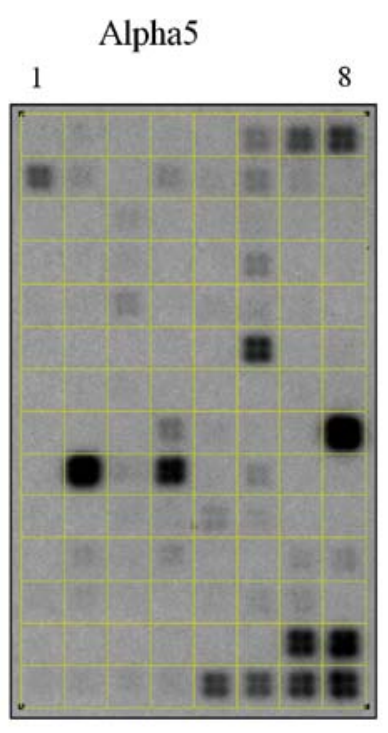

105

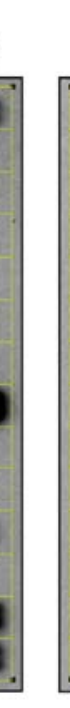

$112 \quad 105$
Tumor2

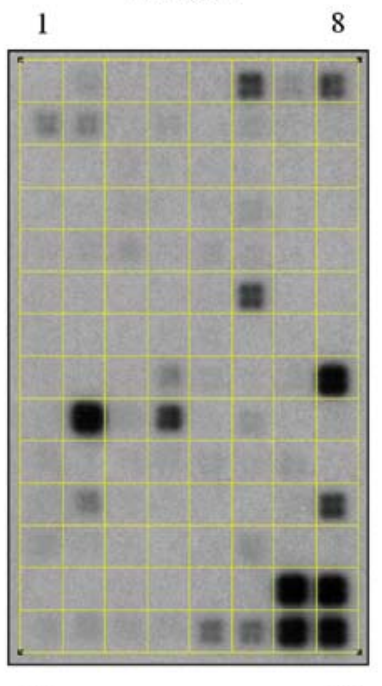

112

Figure 2. cDNA oligoarray related to metastasis genes. Human tumor metastasis gene-specific cDNA fragments onto GEArray membranes were hybridized with biotin-labeled cDNA probes synthesized from total-RNA generated from the MCF-10F, Alpha5 and Tumor2 cell lines.

Photoshop software to obtain the relative grade of luminescence to calculate the fold-change of the expression.

Hydrogen peroxide treatment. To analyze the influence of oxidative stress in the protein expression of the metastasis suppressor CD44 and the antioxidant enzyme MnSOD, cells were treated with different doses of hydrogen peroxide $(100,200,400$ and $800 \mu \mathrm{M}$ ) (Sigma-Aldrich) for 2 days. Then, cells at $70 \%$ of confluence were trypsinized and the collected pellet was stored at $-80^{\circ} \mathrm{C}$ until further analyses.
Western blot analysis. To confirm that gene expression was in accordance to the expression of selected genes an immunodetection technique was performed. Protein was extracted by lysing cells in extraction buffer $(50 \mathrm{mM}$ Tris- $\mathrm{HCl}, \mathrm{pH} 8.0$, $130 \mathrm{mM} \mathrm{NaCl}, 1 \%$ (w/v) NP-40, $1 \mathrm{mM}$ phenylmethylsulfonyl fluoride, $5 \mathrm{mM} \mathrm{MgCl}$ and $1 \mathrm{mM}$ orthovanadate). The protein concentration was determined by the Bicinchoninic Acid Protein Assay kit (Sigma-Aldrich). Equivalent amounts of the protein $(25 \mu \mathrm{g})$ were separated by electrophoresis on an SDS-polyacrylamide gel and subsequently transferred 
Table III. Metastatic genes differentially expressed in the tumorigenic cell lines.

\begin{tabular}{llcc}
\hline Array location & \multicolumn{1}{c}{ Gene name (symbol) } & MCF-10F & Alpha5 \\
\hline 6 & Caveolin-1 (CAV1) & - & Tumor2 \\
7 & CD44 (CD44) & - & $\uparrow$ \\
14 & Cathepsin D (CTSD) & - & - \\
82 & Plasminogen activator inhibitor type 1 (PAI-1) & $\downarrow$ & $\downarrow$ \\
\hline
\end{tabular}

Up-regulated expression $(\uparrow)$. Ratio $\geq 2.0$ related to the control. Down-regulated expression $(\downarrow)$. Ratio $\leq 0.5$ related to the control. No change $(-)$. Unchanged if the ratio was between $>0.5$ and $<2.0$ related to control.

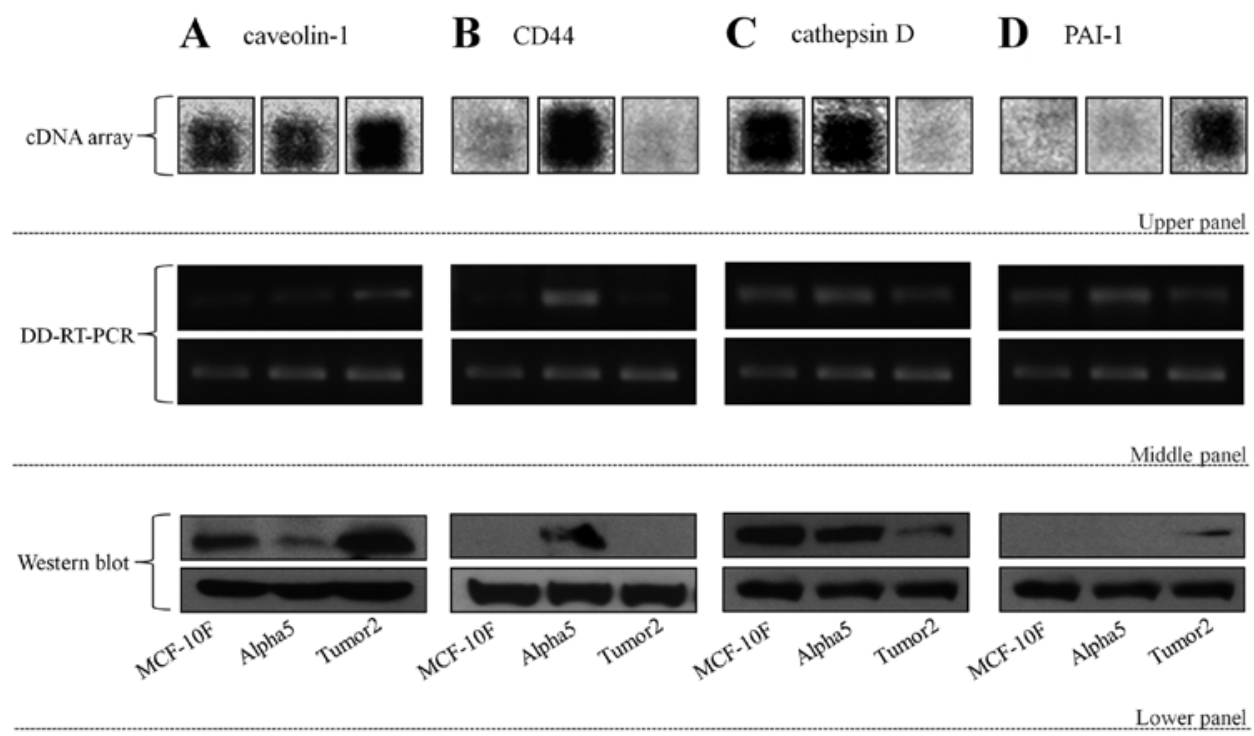

Figure 3. Validation of differential gene expression. Upper panel, intensity of spots of the cDNA array. Middle panel, gene validation with differential displayreverse transcriptase-polymerase chain reaction (DD-RT-PCR). Lower panel, protein expression using Western blot analysis. The image shows the gene and protein expression of (A) caveolin-1, (B) CD44, (C) cathepsin D and (D) PAI-1.

to PVDF membranes with the Trans-Blot ${ }^{\circledR}$ SD Semi-Dry Electrophoretic Transfer Cell (Bio-Rad, Hercules, CA, USA). Antibodies against caveolin-1 (CAV1; sc-70516), CD44 (sc-7297), cathepsin D (CTSD; sc-13148), plasminogen activator inhibitor type 1 (PAI-1; sc-59633) and MnSOD (sc-133134) (all from Santa Cruz Biotechnology, Santa Cruz, CA, USA) were applied to probe the membranes (dilution 1:500-1:1,000). The secondary antibodies (anti-mouse or anti-rabbit) (from Santa Cruz Biotechnology) were conjugated to horseradish peroxidase (dilution 1:5,000). Signals were detected using the ECL kit SuperSignal West Pico Chemiluminescence Substrate (Thermo Scientific, Rockford, IL) according to the manufacturer's protocol. Kodak BioMax light film (Sigma-Aldrich) was used. An antibody against $\beta$-actin (sc-47778) was used as loading control (dilution 1:8,000).

\section{Results}

The malignant cell lines, Alpha5 and Tumor2, showed alterations in metastatic genes associated with their constitutive oxidative stress state previously analyzed in our laboratory. Particularly, MnSOD, an enzyme that responds to oxidative stress, was observed to be closely related to a metastatic suppressor protein called CD44 in response to hydrogen peroxide treatments.

Differentially expressed genes in a human metastasis array. To uncover the genes that are differentially expressed in relation to the metastatic capabilities between the Alpha5 and Tumor 2 cell lines a cDNA expression microarray technique was used to analyze 96 human metastasis-related genes (Fig. 2). Interestingly, only four genes showed altered expression in the array matrix that were related with cell-cell and cell-matrix interaction molecules $(C A V 1)$, metastasis suppressor genes $(C D 44)$, metastasis-associated proteases $(C T S D)$ and protease inhibitors (PAI-1). The expression of the human $\beta$-actin control amplified set, other housekeeping genes (GAPDH, cyclophilin A and RPL13A), and negative controls ( $p U C 18)$ remained similar in all the cell lines. The up- or down-regulation of these differential expressed genes in the malignant cell lines, Alpha5 and Tumor2, and the counterpart MCF-10F cell line are summarized in Table III.

Gene validation and protein expression of selected genes. CAV1 cDNA expression was up-regulated in the Tumor2 cell line in comparison to the Alpha5 and the control cell line and 
A
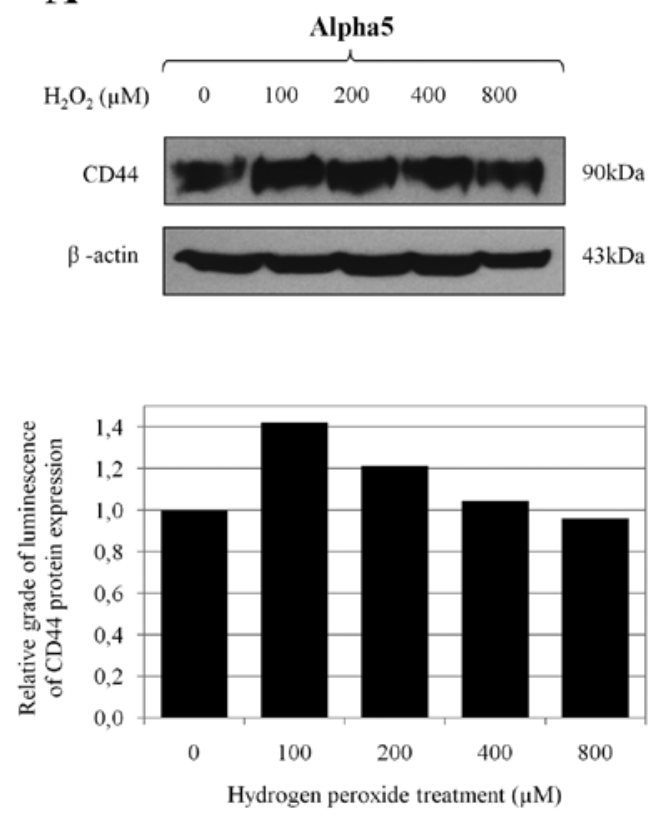

B
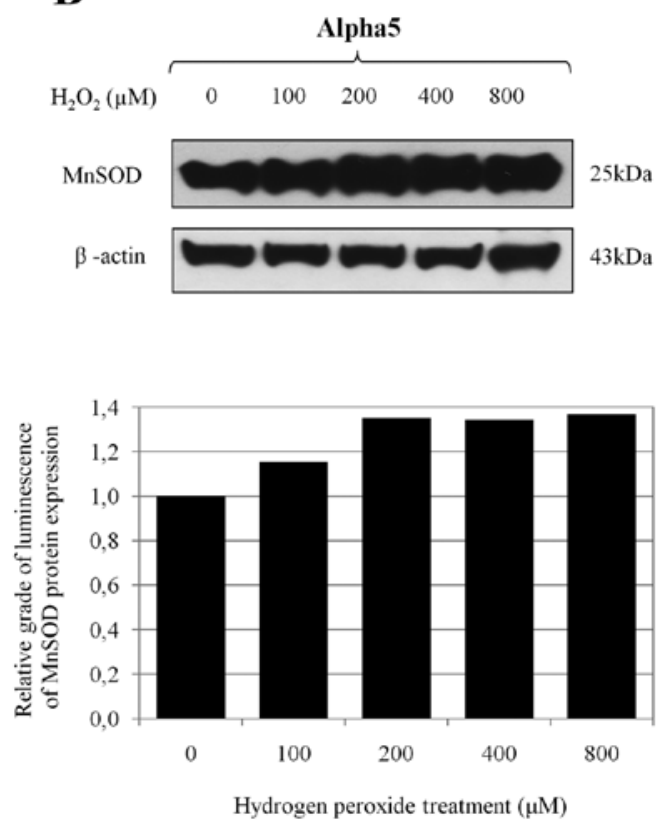

Figure 4. (A) CD44 protein expression in the Alpha5 cell line treated with different doses of hydrogen peroxide (100, 200,400 and $800 \mu \mathrm{M})$. Western blot analysis image of CD44 and $\beta$-actin used as loading control. The graph shows the relative grade of luminescence of the CD44 protein expression. (B) MnSOD protein expression in the Alpha5 cell line treated with different doses of hydrogen peroxide (100, 200, 400 and $800 \mu \mathrm{M})$. The upper panel shows the Western blot analysis image of MnSOD and $\beta$-actin used as a loading control. The graph shows the relative grade of luminescence of the MnSOD protein expression.

the data were confirmed by DD-RT-PCR (Fig. 3A, upper and middle panel). However, the caveolin-1 protein expression was increased in the MCF-10F cell line but was lower than that in the Tumor 2 cell line (Fig. 3A, lower panel). On the other hand, the metastasis suppressor $C D 44$ gene expression was observed to be up-regulated in the Alpha5 cell line in comparison to the control cell line (Fig. 3B, upper and middle panel). The expression of this gene was considerably diminished and it almost disappeared in the Tumor 2 cell line. Furthermore, the CD44 protein expression was not detected in the MCF-10F and Tumor 2 cells in agreement with the gene expression profile (Fig. 3B, lower panel). The array showed that Cathepsin D (CTSD) was expressed in the Alpha5 cells at similar levels to the MCF-10F cells and the expression was down-regulated in the Tumor 2 cell line. This expression pattern was validated by DD-RT-PCR (Fig. 3C, upper and middle panel). CTSD protein expression levels were similar to the gene expression (Fig. 3C, lower panel). Finally, PAI-1 was not expressed in the Alpha5 and MCF-10F cell lines and was down-regulated in the Tumor 2 cell line in an array matrix, but this expression could not be corroborated by DD-RT-PCR (Fig. 3D, upper and middle panel). However, the immunoblotting revealed that PAI-1 protein expression matched with the gene expression pattern obtained from the cDNA array system (Fig. 3D, lower panel).

ROS stimulus decreases CD44 protein expression in the Alpha5 cell line. Among the four genes altered in the cDNA array, was CD44, a metastatic suppressor gene. It was thus interesting to determine whether CD44 protein expression in Alpha5, a malignant but not aggressive cell line, was dependent upon oxidative stress levels. Therefore, CD44 protein expression was assessed at different doses of hydrogen peroxide (100,
$200,400$ and $800 \mu \mathrm{M})$ in the Alpha5 cell line. Results showed (Fig. 4A) that CD44 expression was increased by the hydrogen peroxide treatment reaching a peak at $100 \mu \mathrm{M}$ in comparison to $0 \mu \mathrm{M}$. After hydrogen peroxide treatment with doses from 200 to $800 \mu \mathrm{M}$ a decrease of CD44 expression was observed. Since our previous studies have indicated that MnSOD is correlated with the expression of the non-aggressive phenotype of the tumorigenic Alpha5 cell line, it was important to know the reaction of MnSOD under ROS stimuli in Alpha5 cells and if this expression is correlated with the changes that occur in CD44. The protein expression was determined at different hydrogen peroxide levels from 0 to $800 \mu \mathrm{M}$ (Fig. 4B). The results showed that MnSOD expression increased from 0 to $100 \mu \mathrm{M}$ with hydrogen peroxide treatment reaching a peak at $200 \mu \mathrm{M}$ and plateauing from 200 to $800 \mu \mathrm{M}$. Therefore, a compensatory response of MnSOD to decreased CD44 protein expression in the Alpha5 cell line was observed.

\section{Discussion}

The aim of the present study was to establish the metastatic potential of two malignant and tumorigenic cell lines from a pre-existent in vitro breast cancer model. It was necessary to know whether these malignant cells show differences in the ability to invade new tissues due to differences in the basal oxidative stress condition.

In many studies the high level of MnSOD has been linked to metastasis, proliferation and resistance to apoptosis (29-31). In such cases the overexpression of MnSOD was accompanied with loss of catalase enzyme resulting in an increase of hydrogen peroxide (32-35) which in those studies promoted malignancy progression. However, previous reports of our laboratory (17) have shown that overexpression of MnSOD, linked 
with overexpression of the catalase enzyme and high levels of hydrogen peroxide was able to maintain cell growth of the malignant breast cells under similar conditions in comparison to their normal counterpart. The differential metastatic genes that were observed in this study seem to appear in response to the sets of molecular characteristics triggered by ROS and by the expression of enzymes for antioxidative defense.

Changes in the cell-cell and cell-matrix interaction molecules, such as the caveolins were observed in the array to be differentially expressed. The caveolins are the principal components of caveolae and are also present on the surface of the cell (36). Among this family of proteins, CAV1 has a pivotal role in tumorigenesis through several functions such as lipid transport, membrane trafficking, gene regulation and signal transduction (37). Contradictory data exist in several reports about the expression of this protein in tumorigenesis and metastasis. Meanwhile, in vitro data support the high tumoral growth related to diminished caveolin expression, whereas in vivo studies show that CAV1 is overexpressed in solid tumors correlating with enhancing tumoral cell survival, aggressiveness, metastatic potential, apoptosis suppression (38-41), multiple drug resistance and chemotherapy resistance (43). On the other hand, CAV1 is considered a tumor suppressor protein and it is present in one third of human breast cancers $(42,43)$. For that reason, in early stages a decrease in CAV1 protein expression has been observed associated with proliferation and tumoral growth. The presence of CAV1 is an early event in tumor progression but mutations that occur in such protein in an advanced state enhance the function as an activated oncogene (44). It is thus important to state that the Alpha5 cell line was originated under in vitro requirements, but the Tumor2 was originated under in vivo microenvironmental conditions. In in vivo conditions, represented by the Tumor2 cell line, the cells are subjected to multiple aggressive interactions (45) and CAV1 overexpression allows tumorigenic cell survival and metastatic conditions as shown in this study. It has also been shown that CAV1 expression has been enhanced in metastatic strain variants $(39,46,47)$.

Another differentially expressed gene in the cDNA array was CD44, a transmembrane glycoprotein related with the cell adhesion capacity. CD44 overexpression has been correlated to patient survival $(48,49)$. CD44 is overexpressed in a tubular carcinoma, a subtype of ductal breast cancer that rarely metastasize in comparison to invasive micropapillary carcinoma which has a high metastatic potential and low rate of clinical patient survival (50). The suppression of CD44 expression resulted in a strong induction of metastasis in a lung rat model, but did not affect the size and tumor formation (28). Since in the present study CD44, considered a tumor suppressor gene, was shown to be down-regulated in Tumor2 cells it is possible to assume that Tumor2 has a higher potential to metastasize than the Alpha5 cell line.

The expression of CTSD, a gene related with metastasisassociated proteases, varied between the Alpha5 and Tumor2 cell lines. Studies (51) have demonstrated that in lymphoid cells CTSD is a gene regulated by p53, with a pivotal role in apoptosis and a tumor suppressor function. The regulation of p53 over CTSD has been reported to be independent of apoptotic stimuli. Wu et al (51) showed that in mice CTSD was overexpressed by the p53 expression. They found that CTSD is probably a determinant in the resistance to chemosensitivity since $\mathrm{CTSD}^{-/}$fibroblasts enhanced the resistance to drugs used in chemotherapies, such as adriamycin and etoposide, in comparison with $\mathrm{CTSD}^{+/+}$fibroblasts. Our previous studies (10) showed that mutant p53 (mp53) was overexpressed in the Tumor 2 cell line. In accordance with these findings it is possible to suggest that the Tumor 2 cell line would be more aggressive than the Alpha5 due to p53 expression in addition to suppressed CTSD expression. Our results are in agreement with observations from other authors (52) suggesting that basal oxidative stress in breast cancer cells may accelerate the selection of p53 knockout tumor cell clones, resulting in an apoptotic resistant phenotype.

On the other hand, plasminogen activator inhibitor type-1 (PAI-1) is a member of the superfamily of serine protease inhibitors $(53,54)$. PAI-1 plays a key role in cancer invasion and metastasis through modulation of adhesion and migration pathways (55). This protein has been found to be overexpressed in the cells surrounding the tumors (56). The overexpression of this protein activates various proteases, increasing invasion and the likelihood of metastasis (52). The proteins from the plasminogen activator family have been able to enhance both cell proliferation $(57)$ and migration $(58,59)$ similarly to the observations in the present study in which the expression of such protein the Tumor 2 cell line was related to an aggressive phenotype.

One of the four genes selected from the array, CD44, seems to be particularly interesting since it is considered a metastatic suppressor. CD44 is the major receptor for hyaluronan (HA), in response to different oxidative stress levels. Hyaluronan, known as hyaluronic acid, is a determinant of cellular behavior and promotes multiple processes like anchorage-independent growth, survival, migration, cytotoxicity resistance, among others characteristics that promote metastasis (60-62). HA is able to induce CD44 expression (63) and fragment formation of HA that can induce the cleavage of CD44 (64). It was found that CD44 expression was diminished between $200-800 \mu \mathrm{M}$ of hydrogen peroxide treatment. These results can be explained by the fact that hydrogen peroxide has been reported to induce HA degradation (27). It has also been reported that over $200 \mu \mathrm{M}$ of hydrogen peroxide concentration enhanced the catalysis of HA (65). Others (66) have shown that $100 \mu \mathrm{M}$ of this substance resulted in an overexpression of CD44 maintaining its metastasis suppressor condition. They found that low doses of hydrogen peroxide stimulated HA synthesis in fibroblasts that supports the notion that the biological function of HA is to protect the cell from damage caused by radicals produced by oxidative reductive systems. Our present results showed that MnSOD expression increased from 0 to $100 \mu \mathrm{M}$ with hydrogen peroxide treatment reaching a plateau from 200-800 $\mu \mathrm{M}$. Interestingly, we found that the decrease of CD44 protein expression was correlated with an increase in MnSOD protein expression and it had a concomitant increase of hydrogen peroxide concentrations. Thus, it can be suggested that HA degradation influences the compensatory effect of MnSOD expression as an antioxidant defense (27).

The present results suggest that the alterations shown in the array are pivotal in metastasis-related gene expression and may account for their significant differences in tumorigenic and metastatic capabilities that favor a more aggressive phenotype in breast cancer. The metastatic condition of malignant cells seems 
to be related to a basal oxidative stress state. Furthermore, MnSOD expression seems to be monitoring CD44 expression considered a tumor suppressor gene besides it antioxidant function.

\section{Acknowledgements}

The technical assistance of Ms. Susana Alfaro Lira and the support given by FONDECYT (\#1080482) (GMC) are greatly appreciated.

\section{References}

1. D'Autreaux B and Toledano MB: ROS as signalling molecules: mechanisms that generate specificity in ROS homeostasis. Nat Rev Mol Cell Biol 8: 813-824, 2007.

2. Fruehauf JP and Meyskens FL Jr: Reactive oxygen species: a breath of life or death? Clin Cancer Res 13: 789-794, 2007.

3. Ushio-Fukai M and Nakamura Y: Reactive oxygen species and angiogenesis: NADPH oxidase as target for cancer therapy. Cancer Lett 266: 37-52, 2008.

4. Clerkin JS, Naughton R, Quiney C and Cotter TG: Mechanisms of ROS modulated cell survival during carcinogenesis. Cancer Lett 266: 30-36, 2008.

5. Giles GI: The redox regulation of thiol dependent signaling pathways in cancer. Curr Pharm Des 12: 4427-4443, 2006.

6. Kheradmand F, Werner E, Tremble P, Symons M and Werb Z: Role of Rac1 and oxygen radicals in collagenase-1 expression induced by cell shape change. Science 280: 898-902, 1998.

7. Ben Mahdi MH, Andrieu V and Pasquier C: Focal adhesion kinase regulation by oxidative stress in different cell types. IUBMB Life 50: 291-299, 2000

8. Nabeshima K, Inoue T, Shimao Y and Sameshima T: Matrix metalloproteinases in tumor invasion: role for cell migration. Pathol Int 52: 255-264, 2002.

9. Nelson KK and Melendez JA: Mitochondrial redox control of matrix metalloproteinases. Free Radic Biol Med 37: 768-784, 2004.

10. Li H, Kantoff PW, Giovannucci E, et al: Manganese superoxide dismutase polymorphism, prediagnostic antioxidant status, and risk of clinical significant prostate cancer. Cancer Res 65: 2498-2504, 2005.

11. Poola I, DeWitty RL, Marshalleck JJ, Bhatnagar R, Abraham J and Leffall LD: Identification of MMP-1 as a putative breast cancer predictive marker by global gene expression analysis. Nat Med 11: 481-483, 2005.

12. Friedl $P$ and Wolf K: Tumour-cell invasion and migration: diversity and escape mechanisms. Nat Rev Cancer 3: 362-374, 2003

13. Steeg PS: Tumor metastasis: mechanistic insights and clinical challenges. Nat Med 12: 895-904, 2006

14. Oxmann D, Held-Feindt J, Stark AM, Hattermann K, Yoneda T and Mentlein R: Endoglin expression in metastatic breast cancer cells enhances their invasive phenotype. Oncogene 27: 3567-3575, 2008.

15. Calaf GM and Hei TK: Establishment of a radiation and estrogeninduced breast cancer model. Carcinogenesis 21: 769-776, 2000.

16. Calaf GM, Emenaker NJ and Hei TK: Effect of retinol on radiationand estrogen-induced neoplastic transformation of human breast epithelial cells. Oncol Rep 13: 1017-1027, 2005.

17. Echiburú-Chau C, Roy D and Calaf GM: Deleterious MnSOD signals lead to abnormal breast cell proliferation by radiation and estrogen exposure. Int J Oncol 38: 1703-1711, 2011.

18. Ray G, Batra S, Shukla NK, et al: Lipid peroxidation, free radical production and antioxidant status in breast cancer. Breast Cancer Res Treat 59: 163-170, 2000.

19. Connor KM, Hempel N, Nelson KK, et al: Manganese superoxide dismutase enhances the invasive and migratory activity of tumor cells. Cancer Res 67: 10260-10267, 2007.

20. Li N, Oberley TD, Oberley LW and Zhong W: Overexpression of manganese superoxide dismutase in DU145 human prostate carcinoma cells has multiple effects on cell phenotype. Prostate 35: 221-233, 1998

21. Cullen JJ, Weydert C, Hinkhouse MM, et al: The role of manganese superoxide dismutase in the growth of pancreatic adenocarcinoma. Cancer Res 63: 1297-1303, 2003.
22. Li JJ, Oberley LW, St Clair DK, Ridnour LA and Oberley TD Phenotypic changes induced in human breast cancer cells by overexpression of manganese-containing superoxide dismutase. Oncogene 10: 1989-2000, 1995.

23. Hyoudou K, Nishikawa M, Kobayashi Y, Ikemura M, Yamashita F and Hashida M: SOD derivatives prevent metastatic tumor growth aggravated by tumor removal. Clin Exp Metastasis 25: 531-536, 2008.

24. Malafa M, Margenthaler J, Webb B,Neitzel L and Christophersen M: MnSOD expression is increased in metastatic gastric cancer. J Surg Res 88: 130-134, 2000.

25. Toh Y, Kuninaka S, Oshiro T, et al: Overexpression of manganese superoxide dismutase mRNA may correlate with aggressiveness in gastric and colorectal adenocarcinomas. Int $\mathbf{J}$ Oncol 17: 107-112, 2000.

26. Punnonen K, Ahotupa M, Asaishi K, Hyoty M, Kudo R and Punnonen R: Antioxidant enzyme activities and oxidative stress in human breast cancer. J Cancer Res Clin Oncol 120: 374-377, 1994.

27. Zhao H, Tanaka T, Mitlitski V, Heeter J, Balazs EA and Darzynkiewicz Z: Protective effect of hyaluronate on oxidative DNA damage in WI-38 and A549 cells. Int J Oncol 32: 1159-1167, 2008.

28. Lopez JI, Camenisch TD, Stevens MV, Sands BJ, McDonald J and Schroeder JA: CD44 attenuates metastatic invasion during breast cancer progression. Cancer Res 65: 6755-6763, 2005.

29. Nonaka Y, Iwagaki H, Kimura T, Fuchimoto S and Orita K: Effect of reactive oxygen intermediates on the in vitro invasive capacity of tumor cells and liver metastasis in mice. Int J Cancer 54: 983-986, 1993.

30. Kahlos K, Soini Y, Paakko P, Saily M, Linnainmaa K and Kinnula VL: Proliferation, apoptosis, and manganese superoxide dismutase in malignant mesothelioma. Int J Cancer 88: 37-43, 2000.

31. Nelson KK, Ranganathan AC, Mansouri J, et al: Elevated sod2 activity augments matrix metalloproteinase expression: evidence for the involvement of endogenous hydrogen peroxide in regulating metastasis. Clin Cancer Res 9: 424-432, 2003.

32. Szatrowski TP and Nathan CF: Production of large amounts of hydrogen peroxide by human tumor cells. Cancer Res 51: 794-798, 1991.

33. Gupta A, Butts B, Kwei KA, et al: Attenuation of catalase activity in the malignant phenotype plays a functional role in an in vitro model for tumor progression. Cancer Lett 173: 115-125, 2001.

34. Nishikawa M, Tamada A, Kumai H, Yamashita F and Hashida M: Inhibition of experimental pulmonary metastasis by controlling biodistribution of catalase in mice. Int J Cancer 99: 474-479, 2002.

35. Kinnula VL and Crapo JD: Superoxide dismutases in malignant cells and human tumors. Free Radic Biol Med 36: 718-744, 2004

36. Hnasko R and Lisanti MP: The biology of caveolae: lessons from caveolin knockout mice and implications for human disease. Mol Interv 3: 445-464, 2003

37. Koleske AJ, Baltimore D and Lisanti MP: Reduction of caveolin and caveolae in oncogenically transformed cells. Proc Natl Acad Sci USA 92: 1381-1385, 1995 .

38. Bender FC, Reymond MA, Bron C and Quest AF: Caveolin-1 levels are down-regulated in human colon tumors, and ectopic expression of caveolin-1 in colon carcinoma cell lines reduces cell tumorigenicity. Cancer Res 60: 5870-5878, 2000.

39. Kato K, Hida Y, Miyamoto M, et al: Overexpression of caveolin-1 in esophageal squamous cell carcinoma correlates with lymph node metastasis and pathologic stage. Cancer 94: 929-933, 2002

40. Mouraviev V, Li L, Tahir SA, et al: The role of caveolin-1 in androgen insensitive prostate cancer. J Urol 168: 1589-1596, 2002.

41. Lavie Y, Fiucci G and Liscovitch M: Up-regulation of caveolae and caveolar constituents in multidrug-resistant cancer cells. J Biol Chem 273: 32380-32383, 1998.

42. Hayashi K, Matsuda S, Machida K, et al: Invasion activating caveolin-1 mutation in human scirrhous breast cancers. Cancer Res 61: 2361-2364, 2001

43. Li T, Sotgia F, Vuolo MA, et al: Caveolin-1 mutations in human breast cancer: functional association with estrogen receptor alphapositive status. Am J Pathol 168: 1998-2013, 2006.

44. Bonuccelli G, Casimiro MC, Sotgia F, et al: Caveolin-1 (P132L), a common breast cancer mutation, confers mammary cell invasiveness and defines a novel stem cell/metastasis-associated gene signature. Am J Pathol 174: 1650-1662, 2009.

45. Carver LA and Schnitzer JE: Caveolae: mining little caves for new cancer targets. Nat Rev Cancer 3: 571-581, 2003. 
46. Yang G, Truong LD, Timme TL, et al: Elevated expression of caveolin is associated with prostate and breast cancer. Clin Cancer Res 4: 1873-1880, 1998.

47. Rajjayabun PH, Garg S, Durkan GC, Charlton R, Robinson MC and Mellon JK: Caveolin-1 expression is associated with high-grade bladder cancer. Urology 58: 811-814, 2001.

48. Berner HS, Suo Z, Risberg B, Villman K, Karlsson MG and Nesland JM: Clinicopathological associations of CD44 mRNA and protein expression in primary breast carcinomas. Histopathology 42: 546-554, 2003.

49. Diaz LK, Zhou X, Wright ET, et al: CD44 expression is associated with increased survival in node-negative invasive breast carcinoma. Clin Cancer Res 11: 3309-3314, 2005.

50. Gong Y, Sun X, Huo L, Wiley EL and Rao MS: Expression of cell adhesion molecules, CD44s and E-cadherin, and microvessel density in invasive micropapillary carcinoma of the breast. Histopathology 46: 24-30, 2005.

51. Wu GS, Saftig P, Peters C and El-Deiry WS: Potential role for cathepsin D in p53-dependent tumor suppression and chemosensitivity. Oncogene 16: 2177-2183, 1998.

52. Brown NS and Bicknell R: Hypoxia and oxidative stress in breas cancer. Oxidative stress: its effects on the growth, metastatic potential and response to therapy of breast cancer. Breast Cancer Res 3: 323-327, 2001.

53. Suzuki K, Deyashiki Y, Nishioka J, et al: Characterization of a cDNA for human protein $\mathrm{C}$ inhibitor. A new member of the plasma serine protease inhibitor superfamily. J Biol Chem 262: 611-616, 1987.

54. Silverman GA, Bird PI, Carrell RW, et al: The serpins are an expanding superfamily of structurally similar but functionally diverse proteins. Evolution, mechanism of inhibition, novel functions, and a revised nomenclature. J Biol Chem 276 : 33293-33296, 2001.

55. Fabre-Guillevin E, Malo M, Cartier-Michaud A, et al: PAI-1 and functional blockade of SNAI1 in breast cancer cell migration. Breast Cancer Res 10: R100, 2008.
56. Wilkins-Port CE, Higgins CE, Freytag J, Higgins SP, Carlson JA and Higgins PJ: PAI-1 is a critical upstream regulator of the TGF-beta1/EGF-induced invasive phenotype in mutant p53 human cutaneous squamous cell carcinoma. J Biomed Biotechnol 2007: 85208, 2007.

57. Chorostowska-Wynimko J, Skrzypczak-Jankun E and Jankun J: Plasminogen activator inhibitor type-1: Its structure, biological activity and role in tumorigenesis (Review). Int J Mol Med 13: 759-766, 2004.

58. Samarakoon R, Higgins CE, Higgins SP, Kutz SM and Higgins PJ: Plasminogen activator inhibitor type-1 gene expression and induced migration in TGF-beta1-stimulated smooth muscle cells is pp60(c-src)/MEK-dependent. J Cell Physiol 204: 236-246, 2005.

59. Wang Z, Sosne G and Kurpakus-Wheater M: Plasminogen activator inhibitor-1 (PAI-1) stimulates human corneal epithelial cell adhesion and migration in vitro. Exp Eye Res 80: 1-8, 2005.

60. Toole BP: Hyaluronan: from extracellular glue to pericellular cue. Nat Rev Cancer 4: 528-539, 2004.

61. Jaracz S, Chen J, Kuznetsova LV and Ojima I: Recent advances in tumor-targeting anticancer drug conjugates. Bioorg Med Chem 13: 5043-5054, 2005.

62. Toole BP: Hyaluronan in morphogenesis. J Intern Med 242: 35-40, 1997.

63. Liu CM, Chang CH, Yu CH, Hsu CC and Huang LL: Hyaluronan substratum induces multidrug resistance in human mesenchymal stem cells via CD44 signaling. Cell Tissue Res 336: 465-475, 2009.

64. Sugahara KN, Murai T, Nishinakamura H, Kawashima H, Saya H and Miyasaka M: Hyaluronan oligosaccharides induce CD44 cleavage and promote cell migration in CD44-expressing tumor cells. J Biol Chem 278: 32259-32265, 2003.

65. Soltes L, Kogan G, Stankovska M, et al: Degradation of high-molar-mass hyaluronan and characterization of fragments. Biomacromolecules 8: 2697-2705, 2007.

66. Balaza EA, Davies JV, Phillips GO and Young MD: Transient intermediates in the radiolysis of hyaluronic acid. Radiat Res 31: 243-255, 1967. 